\title{
Polymer-derived ceramic adsorbent for pollutant removal from water
}

\author{
Damla Zeydanli $^{1}$ (D) | Suleyman Akman ${ }^{1}$ | Cekdar Vakifahmetoglu ${ }^{2}$ (D)
}

${ }^{1}$ Department of Chemistry, Istanbul

Technical University, Istanbul, Turkey

${ }^{2}$ Department of Materials Science and

Engineering, Izmir Institute of

Technology, Izmir, Turkey

\section{Correspondence}

Cekdar Vakifahmetoglu, Department of Materials Science and Engineering, Izmir Institute of Technology, Izmir, Turkey. Emails: cekdarvakifahmetoglu@iyte.edu.tr or cvahmetoglu@gmail.com

Funding information

TUBITAK, Grant/Award Number: CAYDAG-113Y533

\begin{abstract}
Polymer-derived ceramic components (SiOC, sample W) were produced from preceramic polymer mixture and a catalyst. After curing and pyrolysis, some of the samples etched by hydrofluoric acid to obtain carbonaceous SiOC (C-rich SiOC, sample $\mathrm{W}-\mathrm{HF}$ ). $\mathrm{W}$ and $\mathrm{W}-\mathrm{HF}$ were tested as an adsorbent material to remove both heavy-metal ions ( $\mathrm{Cr}$ (III), $\mathrm{Pb}$ (III), and $\mathrm{Cd}$ (II)) and cationic dyes (Methylene Blue (MB), Rhodamine B (RB), and Crystal Violet (CV)) from aqueous solutions. HF-treated high surface area SiOC samples had quite high adsorption affinity for cationic dyes. According the Langmuir isotherm model the maximum dye uptake values were found to be around to $50 \mathrm{mg} / \mathrm{g}$ for sample $\mathrm{W}$, whereas those for sample W-HF ranged from 104 to $186 \mathrm{mg} / \mathrm{g}$. Regeneration studies were conducted both by heat treatment and leaching, high recovery yields (always above $97 \%$ ) of MB adsorption were obtained.
\end{abstract}

\section{K E Y W O R D S}

batch adsorption, cationic dyes, hierarchical porous ceramics, metal ions, water purification

\section{1 | INTRODUCTION}

Various strategies such as ion exchange, ${ }^{1}$ photocatalytic activity, ${ }^{2,3}$ chemical precipitation, ${ }^{4,5}$ membrane filtration, ${ }^{6-8}$ and others as detailed in recent reviews ${ }^{9-11}$ have been applied for removing metal ions and/or dyes from aqueous solutions. Adsorption is one of the commonly used technique due to its low cost, high efficiency, and simplicity. ${ }^{12-15}$ Clays, ${ }^{16-18}$ zeolites, ${ }^{19,20,21}$ carbon- or silica-based porous materials ${ }^{22-34}$ have been extensively investigated as an adsorbent for the removal of pollutants.

Considerable efforts are currently devoted to propose new adsorbents or improvement of the adsorption performance. In this context, preceramic polymers (PPs) offer several opportunities since their molecular composition/architecture can be altered easily and they can be processed to obtain in various forms following via plastic forming technique. ${ }^{35-38}$ Ceramics synthesized by the thermal decomposition of PPs, that is, polymer-derived ceramics (PDCs), are novel class of nanostructured materials mostly composed of silicon, carbon, nitrogen, boron, and oxygen (depending on PP composition, heat-treatment procedure: temperature, rate, dwell time, atmosphere, etc.).

Among all PPs polysiloxanes are the most economical ones. They are readily available and can be handled in ambient atmosphere. Pyrolysis in between 800 and $1400^{\circ} \mathrm{C}$ results in the formation of Silicon oxycarbide (SiOC) amorphous material. Fabrication of porous and high surface area PDCs has long been investigated, ${ }^{35,38-40}$ however, there is a relative paucity of scientific reports on specific applications of PDCs. Recently materials obtained through cumbersome processing routes such as PDC aerogels ${ }^{41}$ or composites formed using polysiloxane and wood $^{42}$ were tested as dye adsorbents. However, high surface area amorphous SiOC have never been evaluated for such purpose. In this work, a highly permeable, high surface area SiOC was synthesized, characterized and used for the first time its adsorption capacity for the purification of metal ions (Chromium (III), Lead (II), and Cadmium (II)) and cationic dyes (Methyene Blue (MB), Rhodamine B (RB), Crystal 
Violet (CV) both separately and ternary combined manner) from aqueous solution.

\section{2 | EXPERIMENTAL PROCEDURE}

\subsection{Instrumentation and reagents}

$1000 \mathrm{mg} / \mathrm{L}$ standard solutions $\left(\left(\mathrm{Cr}\left(\mathrm{NO}_{3}\right)_{3}\right.\right.$ CAS\# 13528-38$4), \quad\left(\mathrm{Cd}\left(\mathrm{NO}_{3}\right)_{2} \quad \mathrm{CAS \#} 10325-94-7\right), \quad\left(\mathrm{Pb}\left(\mathrm{NO}_{3}\right)_{2} \quad\right.$ (CAS\# 10099-74-8)), all analytical grade (Merck, Germany) were diluted to desired concentrations prior to experiments. The cationic dyes MB (Merck, Germany, CAS\# 122965-43-9), CV (Merck, Germany, CAS\# 548-62-9) and RB (Merck, Germany, CAS\# 81-88-9), were used without further purification. The maximum and minimum projection radius for analyzed dyes were found as $0.436-0.835 \mathrm{~nm}$ for $\mathrm{MB}$ $\left(\mathrm{C}_{16} \mathrm{H}_{18} \mathrm{~N}_{3} \mathrm{SCl}\right), 0.791-0.812 \mathrm{~nm}$ for $\mathrm{CV}\left(\mathrm{C}_{25} \mathrm{H}_{30} \mathrm{~N}_{3} \mathrm{Cl}\right)$, and 0.723-0.840 for $\mathrm{RB}\left(\mathrm{C}_{28} \mathrm{H}_{31} \mathrm{ClN}_{2} \mathrm{O}_{3}\right){ }^{43}$

The $\mathrm{pH}$ of each solution was adjusted with $\mathrm{NaOH}$ (Merck, Germany, CAS\# 1310-73-2) and $\mathrm{HNO}_{3}$ (Merck, Germany, CAS\# 7697-37-2) or HCl (Merck, Germany, CAS\# 764701-0) using WTW pH 340-A/SET2 pH meter (Weilheim, Germany).

Microstructural characterization of samples was performed using a scanning electron microscope (SEM, FEI Quanta 250 FEG, Hillsboro, OR) equipped with energydispersive X-ray spectrometer (EDX, Oxford instruments, Aztec) for chemical analysis. All samples were coated with $10 \mathrm{~nm} \mathrm{Au}$ film (Emitech K550X sputter coater, London, UK) prior to investigation.

Transmission electron microscopy (TEM, tungsten thermionic source, $120 \mathrm{kV}$ accelerating voltage, Philips CM12, the Netherlands) was used to analyze pore morphology in $\mathrm{W}-\mathrm{HF}$ sample. After grinding in an agate mortar and dispersing in ethanol (EtOH) for 5 minutes, a drop of solution was placed onto a carbon-coated copper grid, followed by drying and analysis.

Thermal gravimetric analysis (TGA) were conducted using Netszch equipment (STA 409 model, NetzschGerätebau $\mathrm{GmbH}$, Selb, Germany) with $5^{\circ} \mathrm{C} / \mathrm{min}$ heating rate of up to $1300^{\circ} \mathrm{C}$ in ambient atmosphere (the same conditions for regeneration studies).

The specific surface area (SSA) was determined by Nitrogen $\left(\mathrm{N}_{2}\right)$ gas adsorption at $77 \mathrm{~K}$ (ASAP model 2010, Norcross, GA). The SSA values were calculated using BET (Brunauer, Emmet, and Teller) equation. The Barrett-Joyner-Halenda (BJH) used to obtain the pore size distribution (PSD). In a previous study, ${ }^{38}$ the SSA values were found $\sim 120 \mathrm{~m}^{2} / \mathrm{g}$ for $\mathrm{W}$ and $\sim 660 \mathrm{~m}^{2} / \mathrm{g}$ for $\mathrm{W}-\mathrm{HF}$ and PSD demonstrated that while sample $\mathrm{W}$ was mostly mesoporous, W-HF had broad pore size distribution in both micro and mesopore range (see Figure S1).
Quantitative determination of all metals was carried out by high-resolution continuum- source air-acetylene flame atomic absorption spectrometer (AAS, ContrAA 700, Analytik Jena, Germany). Measurements were performed at wavelengths of $217.005 \mathrm{~nm}$ for $\mathrm{Pb}, 228.801 \mathrm{~nm}$ for $\mathrm{Cd}$ and, $357.800 \mathrm{~nm}$ for $\mathrm{Cr}$ (III). The concentrations of the $\mathrm{MB}, \mathrm{CV}$, and RB solutions were determined by ultravioletvisible (UV-Vis) spectrometer (UV-2700, Shimadzu, Japan) at the wavelength of 668,589 , and $555 \mathrm{~nm}$, respectively. Infrared spectra were acquired with a Perkin Elmer Spectrum 100 FTIR spectrometer (ZnSe crystal, Perkin Elmer Inc., Wellesley, MA). An average of 40 scans with $4 \mathrm{~cm}^{-1}$ resolution was recorded in $4000-400 \mathrm{~cm}^{-1}$ for each sample. $500 \mathrm{mg} / \mathrm{L}$ dye (MB, RB or CV) was loaded on the $\mathrm{W}$-HF sample before the measurement.

Ultra-pure water with $18.2 \mathrm{M} \Omega \mathrm{cm}$ resistivity was obtained from a TKA reverse osmosis and a TKA deionizer system (TKA Wasseraufbereitungsysteme $\mathrm{GmbH}$, Niederelbert Germany) was used for all experiments. MRC Scientific Industries centrifuge (London, UK) was used for separation.

\section{2 | Materials}

The samples were prepared following the procedure given in the literature. ${ }^{38,44}$ All the starting chemicals were used as received: Hydrotalcite, (LDH: $\mathrm{Mg}_{6} \mathrm{Al}_{2}\left(\mathrm{CO}_{3}\right)$ $\left.(\mathrm{OH})_{16} \cdot 4 \mathrm{H}_{2} \mathrm{O}\right)$, vinyl-terminated polydimethylsiloxane (PDMS, Gelest, USA, CAS\# 68083-19-2) a cyclic 2,4,6,8tetramethyl-2,4,6,8- tetravinlycyclotetrasiloxane (TMTVS 97\%, Alfa Aesar, USA, CAS\# 2554-06-5), and polymethylhydrosiloxane (PHMS, CAS\# 63148-57-2, Gelest,USA), Platinum - divinyltetramethyldisiloxane complex, $\sim \mathrm{Pt} 2 \%$ in xylene (Sigma-Aldrich, USA, CAS\# 68478-92-2). The sample W (referring water) was prepared from the mixture of PHMS/LDH/PDMS/cyclic-TMTVS in a beaker with a weight ratio of $1 / 0.055 / 1 / 0.055$. The blend was mixed at room temperature (RT) for 5 minutes at 500 RPM and after homogenization, $100 \mathrm{ppm}$ by weight of $\mathrm{Pt}$ relative to PHMS was added into the mixture. The blend was further mixed and transferred into aluminum molds standing on the hot plate operating at $200^{\circ} \mathrm{C}$ followed by pyrolysis at $1300^{\circ} \mathrm{C}$ for 1 hour $\left(2^{\circ} \mathrm{C} \mathrm{min}{ }^{-1}\right.$ heating rate, $100 \mathrm{~mL} / \mathrm{min}$ Ar flow, PROTERM PTF 16/75/450, Ankara, Turkey).

The etching process was done using around $250 \mathrm{mg}$ of ground and sieved $(<500$ microns $)$ SiOC sample with $50 \mathrm{ml}$ of $\mathrm{HF}\left(48 \mathrm{vol} \%\right.$ in $\mathrm{H}_{2} \mathrm{O}$ ) solution in PE closed container. ${ }^{45}$ The attack was performed by leaving the sample in contact with the etching solution for 4 days at RT and gently stirring the containers time to time. After the attack SiOC powder (W-HF) was filtered, rinsed with distilled water (several times) and dried at $65^{\circ} \mathrm{C}$ for 24 hours for the subsequent analysis. 


\section{3 | Adsorption procedure}

For all adsorption tests the used samples (both $\mathrm{W}$ and W$\mathrm{HF}$ ) were in powder form below 500 micrometers. The effect of $\mathrm{pH}$, adsorbent dosage and contact time on the adsorption was investigated. Initially, aqueous solution of dyes and metal ions at $\mathrm{pH}$ ranging from 2.0 to 10.0 was prepared to analyze the effect of $\mathrm{pH}$. To find the effective adsorbent dosage and contact time, different adsorbent amounts (1-40 g/L) were studied for a known period (0.572 hours) of contact time. Once the equilibrium was reached, solution and adsorbent were separated by centrifuge (3860 g, 15 minutes). The concentration of heavymetal ions remaining and initial solutions were measured by AAS using flame method. UV-Vis. spectrometer was used for determination of dye concentrations.

The regeneration efficiency was investigated on W-HFMB by following two different methods: (i) Chemical recovery (extraction), and (ii) thermal decomposition. For both techniques $0.5 \mathrm{~g} / \mathrm{L} \mathrm{W}-\mathrm{HF}$ and $200 \mathrm{mg} / \mathrm{L}$ (at $\mathrm{pH}$ 8) MB solution were stirred at $500 \mathrm{rpm} / 24$ hours for saturation. The dye adsorbed W-HF were separated and dried overnight. In chemical recovery (conducted at RT) the material was agitated by ethanol with different $\mathrm{pH}$ (2-10 controlled by $\mathrm{HNO}_{3}$ or $\mathrm{NaOH}$ ) levels. The suspensions were stirred 24 hours and the supernatant solutions were analyzed to estimate the amount of desorbed MB. The samples washed with $0.1 \mathrm{~mol} / \mathrm{L} \mathrm{NaOH}$ solution, rinsed with DI water, dried overnight and reloaded with MB solution under the same conditions.

For the thermal regeneration studies of MB loaded $(200 \mathrm{mg} / \mathrm{L}$ at $\mathrm{pH} 8) \mathrm{W}-\mathrm{HF}$, the sample was heat-treated at $400^{\circ} \mathrm{C}$ for 2 hours $\left(5^{\circ} \mathrm{C} / \mathrm{min}\right.$ heating rate, the TGA data given in Figure S2 shows that W-HF was thermally stable up to this temperature and less than 5 wt.\% loss is observed due to moisture) in a box furnace (ProthermPLF 120, Ankara, Turkey), and after furnace cooling resorption were done. In both regeneration methods, whole adsorption-desorption procedures were repeated for 3 times.

\section{3 | RESULTS AND DISCUSSION}

\subsection{Selection of pH, adsorbent dosage, and contact time}

The highest metal ion sorption (see Figure 1A) occurred at $\mathrm{pH}$ 6, whereas for sorption of dyes $\mathrm{pH} 8$ was optimum for $\mathrm{MB}$ and $\mathrm{CV}$, and instead $\mathrm{pH} 7$ was for $\mathrm{RB}$ (see Figure 1B). These $\mathrm{pH}$ values were used in all the following adsorption tests.

At lower $\mathrm{pH}$ levels, the sorption of metal ions was found to be low; due most probably to the fact that at low
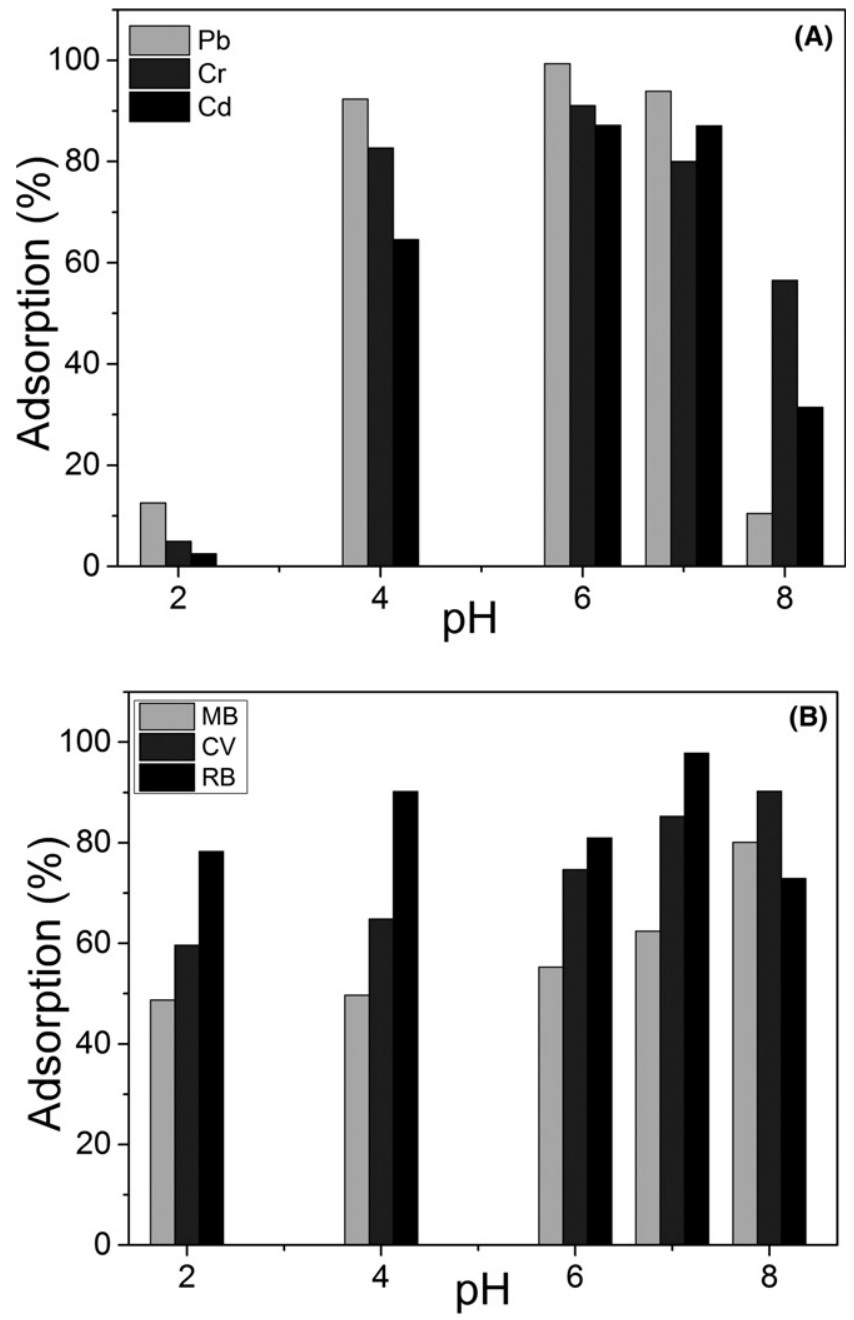

FIGURE 1 The effect of $\mathrm{pH}$ for (A) metal ion sorption (initial metal concentration: $1 \mathrm{mg} / \mathrm{L}$, adsorbent dosage: $5 \mathrm{~g} / \mathrm{L}$ contact time: $2 \mathrm{~h}$ ), (B) cationic dye sorption (initial dye concentration: $25 \mathrm{mg} / \mathrm{L}$, adsorbent dosage: $0.5 \mathrm{~g} / \mathrm{L}$, contact time: $24 \mathrm{~h}$ )

$\mathrm{pH}$ values $\mathrm{H}_{3} \mathrm{O}^{+}$is in competition with $\mathrm{M}^{+}$ions for active sites of the material. The sorption of metals increased above $\mathrm{pH} \mathrm{5}$, reached maximum in between 6 and $7(\geq$ $90 \%$ ) similar to literature data ${ }^{46}$ which can be explained as a result of negatively charged surface due to higher $\mathrm{pH}$, and its affinity to cationic species.

For metal ions $5 \mathrm{~g} / \mathrm{L}$, and for dyes $0.5 \mathrm{~g} / \mathrm{L}$ was selected for further experiments since they were the minimum dosage with the highest removal. For metal ions, 2 hours, and for dyes, 24 hours was found to be sufficient to reach equilibrium even for the highest pollutant concentration studied.

\section{2 | Maximum adsorption capacities}

To find maximum sorption capacities, sorbent dosage, $\mathrm{pH}$, and contact time were kept constant and pollutants were added at different initial concentrations. The amount of 
adsorption per unit of adsorbent at equilibrium $q_{e}(\mathrm{mg} / \mathrm{g})$ was calculated using the following expression given in Equation 1:

$$
q_{e}=\frac{\left(C_{o}-C_{e}\right)}{m} * V
$$

where $C_{O}$ and $C e$ are the concentrations $(\mathrm{mg} / \mathrm{L})$ of analytes (the metal ions or dyes) in the initial and at the equilibrium, respectively; $V(\mathrm{~mL})$ is the solution volume and $m$ ( $\mathrm{g}$ ) is the amount of adsorbent used.

Isotherm equations especially Langmuir and Freundlich are widely used to simulate the adsorption of pollutants on various adsorbent. These two models have different assumptions; whereas Langmuir has been used for monolayer adsorption, Freundlich is commonly selected for adsorption over a heterogeneous surface. ${ }^{47}$ While the experimental data (see Figures 2A-D) were fitted to both of the above-mentioned models, the Freundlich isotherm did not provide a good fit instead Langmuir model showed decent agreement with data.

The values of $q_{m}(\mathrm{mg} / \mathrm{g})$ and $K_{L}(\mathrm{~L} / \mathrm{mg})$ were found from the slope of a straight line and intercept of the $C_{e} / q_{\mathrm{e}}$ vs $C_{e}$ plot. The obtained parameters and correlation coefficients $\left(R^{2}\right)$ are given in Table 1 .

\subsection{1 | Removal of metal ions}

The metal ion adsorption capacities were found to be in the range of 2.7-5.6 mg/g for Cd (II), 3.4-5.6 mg/g for $\mathrm{Pb}$ (II), and 3.7-4.0 mg/g for $\mathrm{Cr}$ (III). The HF etching of SiOC material changed the surface chemistry and pore morphology by attacking Si-O bonds, causing enhanced surface area and more negative surface resulting in further adsorption sites for cations. ${ }^{45}$ There are no studies in the literature to compare the metal ion adsorption behavior of SiOC, still the $\mathrm{q}_{\mathrm{m}}$ values for $\mathrm{Cd}$ (II), $\mathrm{Pb}$ (II), and $\mathrm{Cr}$ (III) are low. Although for simplicity, SiOC can be considered as a material comprised of both carbon and silica "phases," and adsorption capacity can be compared with such materials, such indirect assessment is still ambiguous due to lack of consistency in the literature. For example, Cd (II) adsorption by carbon aerogels resulted in diverse values; while $426 \mathrm{~m}^{2} / \mathrm{g}$ surface area material gave adsorption capacity of $400.80 \mathrm{mg} / \mathrm{g}$, aerogel with $700 \mathrm{~m}^{2} / \mathrm{g} \mathrm{SSA}$ resulted in a lower value of $15.53 \mathrm{mg} / \mathrm{g}$, similar to mesoporous silica with SSA of $550 \mathrm{~m}^{2} / \mathrm{g}$ demonstrated $15 \mathrm{mg} / \mathrm{g}$ capacity for Cd (II).

\subsection{2 | Removal of dyes}

The capacities of the samples tested for dyes were found to be always high being around $50 \mathrm{mg} / \mathrm{g}$ for sample $\mathrm{W}$, and in between $\sim 104$ to $\sim 186 \mathrm{mg} / \mathrm{g}$ for etched sample (W-HF). The effect of HF treatment was clearly more pronounced for dye adsorption compared with that of metal ions. In this regard, more detailed characterization was conducted and the adsorption of dye molecules on HF-treated SiOC, that is C-rich SiOC, were further followed by FTIR, SEM, and TEM.

FTIR data given in Figure 3A were obtained from pure dyes. Instead in Figure 3B) data for the samples before and after dye adsorption are given. The W-HF had a shoulder centering around $1010 \mathrm{~cm}^{-1}$ attributed to $\mathrm{Si}-\mathrm{O}$ stretching vibration of $\mathrm{Si}-\mathrm{O}-\mathrm{Si}$ or $\mathrm{Si}-\mathrm{O}-\mathrm{C}$ units. Another distinct
FIGURE 2 Adsorption data for metal ions: (A) on $\mathrm{W}$, (B) on W-HF, similarly adsorption data for dyes (C) on W, and (D) on $\mathrm{W}-\mathrm{HF}$
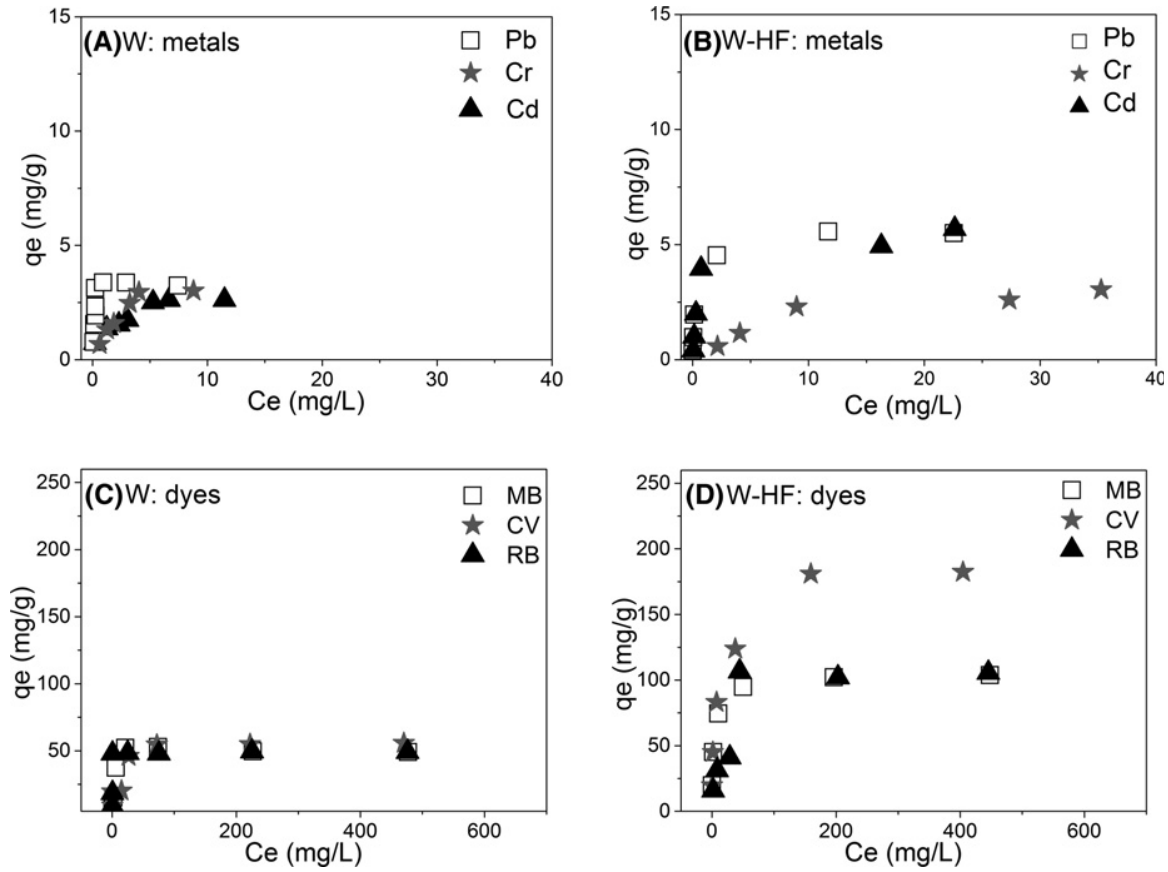
T A B LE 1 Data from Langmuir isotherm fit both for W and W-HF sample

\begin{tabular}{|c|c|c|c|c|c|c|c|c|}
\hline Adsorbent & Metal & $\mathrm{q}_{(\mathrm{m}}$ & $\begin{array}{l}K_{L} \\
(\mathrm{~L} / \mathrm{mg})\end{array}$ & $R^{2}$ & Dye & $\underset{(\mathrm{mg} / \mathrm{g})}{\mathrm{q}_{\mathrm{m}}}$ & $\begin{array}{l}\mathbf{K}_{\mathrm{L}} \\
(\mathrm{L} / \mathrm{mg})\end{array}$ & $R^{2}$ \\
\hline \multirow[t]{2}{*}{ W } & $\mathrm{Cd}$ (II) & 2.67 & 1.66 & 0.972 & $\mathrm{MB}$ & 49.26 & 1.70 & 0.999 \\
\hline & $\mathrm{Cr}$ (III) & 4.04 & 0.39 & 0.958 & $\mathrm{RB}$ & 49.38 & 1.05 & 0.999 \\
\hline \multirow[t]{2}{*}{ W-HF } & $\mathrm{Cd}$ (II) & 5.59 & 1.44 & 0.991 & $\mathrm{MB}$ & 104.27 & 0.05 & 0.999 \\
\hline & $\mathrm{Cr}$ (III) & 3.73 & 0.11 & 0.959 & $\mathrm{RB}$ & 110.74 & 0.31 & 0.990 \\
\hline
\end{tabular}

band can be seen at $\sim 800 \mathrm{~cm}^{-1}$ is due to the $\mathrm{Si}-\mathrm{C}$ stretching vibrations, similar to previously obtained data for $\mathrm{HF}$ treated SiOC samples. ${ }^{4,48}$ While further studies required to reveal the observations related with FTIR data, it is known that the $\mathrm{C}=\mathrm{C}$ and $\mathrm{C}-\mathrm{N}$ aromatic bonds associated with $\mathrm{MB}$, $\mathrm{RB}$, and $\mathrm{CV}$ appear in the range of $1000-1600 \mathrm{~cm}^{-1}$ (see Figure 3A). ${ }^{49-51}$ As can be seen from Figure $3 \mathrm{~B}$ while there are no peaks visible in the data for the sample W-HF in such range, the sample after dye adsorption evidently demonstrates new bonds indicating that dyes were effectively loaded on the surface of the W-HF sample. ${ }^{41}$
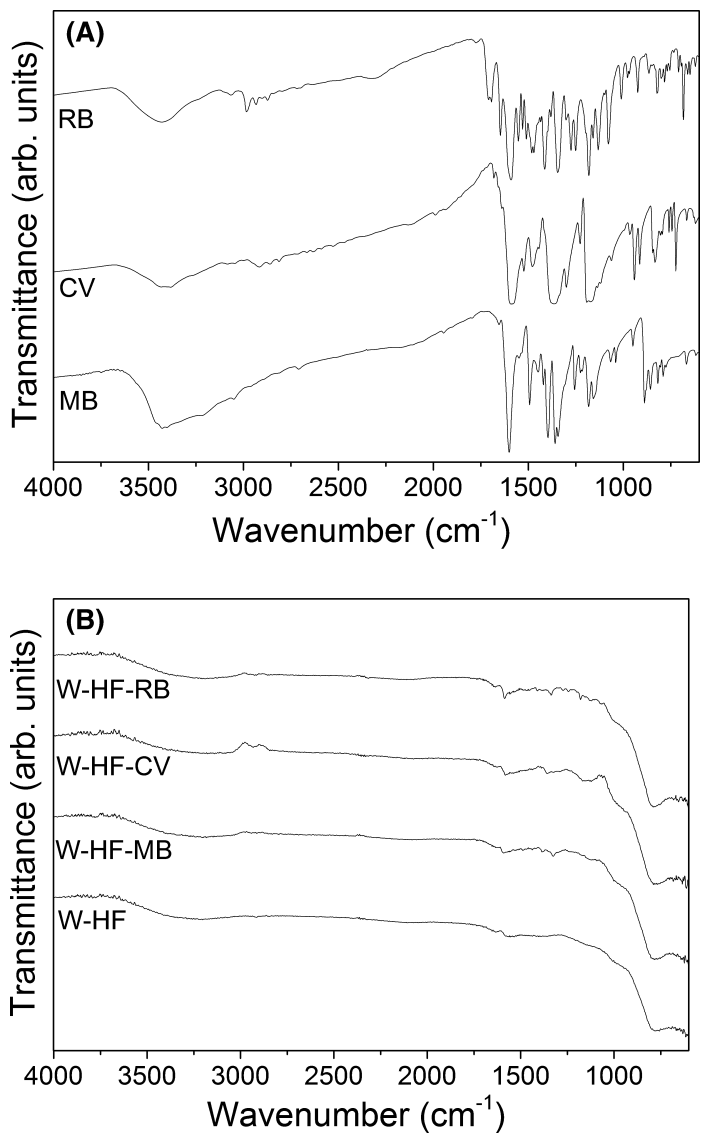

F IG URE 3 FTIR data of the (A) used dyes; and (B) samples without (W-HF) and with dye adsorption (i.e. W-HF-MB, W-HF-CV, and W-HF-RB)
The micrographs show before (Figures 4A) and after (Figure 4B-C-D) dye adsorption on W-HF. From the low magnification SEM image (see Figure S3(a)) irregular particles of around $200 \mu \mathrm{m}$ can be seen. Detailed analysis from higher magnification (Figure 4A) displays rough and porous surface, typical of HF-treated SiOC. ${ }^{45}$ The TEM image (see inset of Figure 4A) taken from the sample clearly demonstrates both macro and mesopores. As expected after dye adsorption, the particle morphology did not alter (see Figure S3(b)), but higher magnification analysis (Figure 4B-C-D) revealed the formation of relatively smooth coating layer and surface pore closure. EDX was used to investigate the chemical composition alterations upon MB adsorption. While the analysis (see Figure S5(a) and Table S1) from the sample W-HF gave only $\mathrm{Si}, \mathrm{O}, \mathrm{C}$, and $\mathrm{Mg}$ (due to $\mathrm{LDH}$ ), in the MB-coated sample new peak observed (see Figure S5(b) and Table S1) attributed to sulfur $(\mathrm{S})$ corroborates furthermore the adsorption of $\mathrm{MB}$ on the $\mathrm{W}-\mathrm{HF}$ surface.

Scattered results are similarly available for dye adsorption in porous materials (e.g. MB adsorption on activated carbon was evaluated with $1.33 \mathrm{mg} / \mathrm{g}$ capacity for 736$793 \mathrm{~m}^{2} / \mathrm{g}$ surface area carbon, ${ }^{28}$ and $594 \mathrm{mg} / \mathrm{g}$ capacity for $180 \mathrm{~m}^{2} / \mathrm{g} \mathrm{SSA}$ carbon $^{29}$ ). However, it is still possible to extract information from silica-based materials. Comparison done with high surface area (SSA of $757 \mathrm{~m}^{2} / \mathrm{g}$ ) mesoporous silica having $113 \mathrm{mg} / \mathrm{g}$ capacity, ${ }^{27}$ with composite made of $\mathrm{SiOC}+$ wood $\left(463.1 \mathrm{~m}^{2} / \mathrm{g}\right)$ having $173.5 \mathrm{mg} / \mathrm{g}$ capacity, $^{42}$ and with SiOC aerogel $\left(163 \mathrm{~m}^{2} / \mathrm{g}\right)$ having $42.2 \mathrm{mg} / \mathrm{g}$ capacity ${ }^{41}$ (all tested with MB) indicates that the both $\mathrm{W}$ and $\mathrm{W}-\mathrm{HF}$ showed consistent results with literature. Sample W having surface area of $\sim 120 \mathrm{~m}^{2} / \mathrm{g}$ and $\mathrm{W}$ $\mathrm{HF}$ with $\sim 660 \mathrm{~m}^{2} / \mathrm{g}$ resulted in the MB adsorption capacity of $49.3 \mathrm{mg} / \mathrm{g}$ and $104.3 \mathrm{mg} / \mathrm{g}$, respectively. As could be seen in Table 1 similar results obtained for other dyes, and only W-HF has slightly higher affinity for $\mathrm{CV}$ due most probably to the difference in the size selectivity ${ }^{52}$ and/or other types of interactions. ${ }^{53}$

It is possible to state that the pronounced adsorption for dyes compared with that of metal ions can be attributed to $\mathrm{Si}-\mathrm{OH}$ bonds (available in SiOC and more in HF-treated 

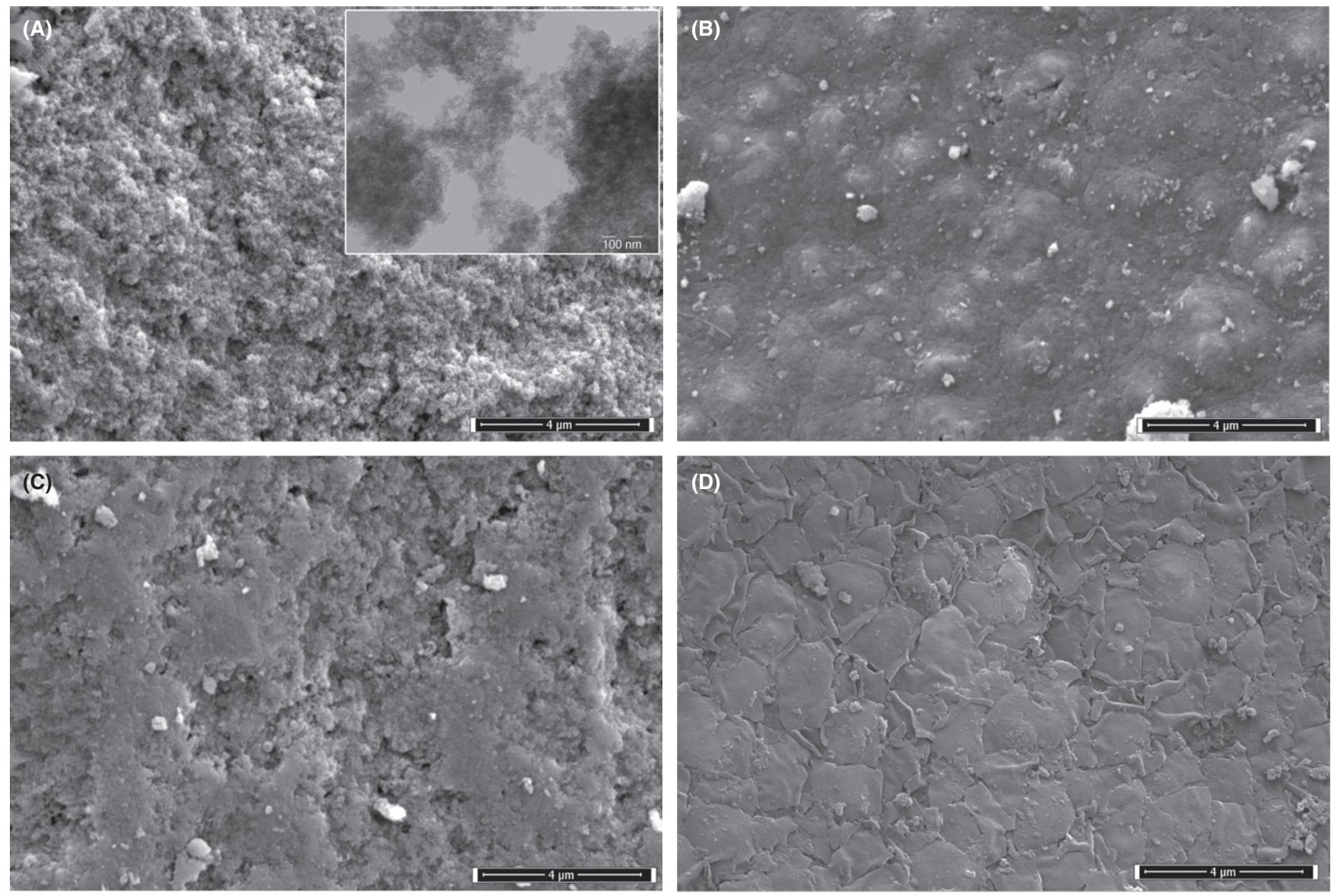

F I G U RE 4 Electron microscopy images: (A) SEM image showing W-HF sample's rough and porous surface, and the inset TEM image taken from the same sample demonstrates both macro and mesoporosity. SEM images of the samples after dye adsorption; (B) W-HF-MB, (C) W-HF-RB, and (D) W-HF-CV

$\mathrm{SiOC}^{45}$ ) and free carbon both of which may interact with the organic dyes ${ }^{41}$ through (a) Van der Waals forces between the dyes and the sp2 hybridized carbon, and (b) the electrostatic interaction between $\mathrm{Si}-\mathrm{OH}$ and/or the carbon-oxygen complexes present.

Further experiments were done using ternary mixture of $\mathrm{MB}, \mathrm{CV}$ and RB on W-HF. ${ }^{54} 0.005 \mathrm{~g}$ of W-HF was mixed with $10 \mathrm{~mL}$ solution (each dye with $25 \mathrm{mg} / \mathrm{L}$ concentration), mixed for different times (1, 2, 4, 8, and 24 hours). At the end of each mixing time, the solution was centrifuged, filtered and analyzed. The efficiency for ternary dye mixture upon 24 hours contact time were above $99 \%$, digital photo taken from different contact times is given in Figure S4.

\section{3 | Regeneration studies}

Regeneration were followed both by thermally ${ }^{55,56}$ and chemically (extraction) using ethanol. ${ }^{57}$ Recovery tests were applied only for selected dye (200 ppm MB was chosen considering the saturation point of MB on W-HF, see Figure 2D) on the selected sample W-HF. Three cycles of

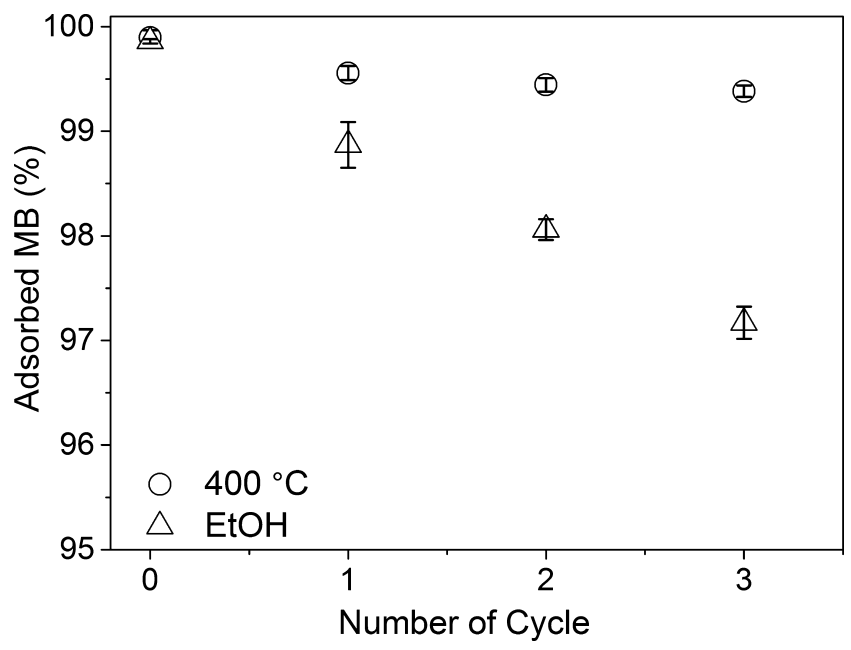

F IG URE 5 Resorption yields for MB (200 mg/L) on W-HF which initially adsorbed $99.88 \% \mathrm{MB}$

adsorption-desorption were carried out and MB resorption $\%$ values are reported in Figure 5. The maximum dye recovery by ethanol obtained at $\mathrm{pH} 2$, and the readsorption value decreased to $97 \%$ after 3 rd cycle. It should also be 
noted that such high acidic environment may also alter the structure of W-HF. Instead via thermal treatment quite good reusability was observed reaching above $99 \%$ even after 3rd cycle, surpassing the performance of $\mathrm{SiCN}$ hybrid material. ${ }^{58}$

\section{4 | CONCLUSION}

The experimental results indicated that HF-treated SiOC (W-HF) has limited adsorption capacity for metal ions but could be very effectively used to remove cationic dyes from aqueous solutions over a wide range of concentrations. Equilibrium data fitted well with Langmuir model giving adsorption capacity of $104 \mathrm{mg} / \mathrm{g}$ (MB), $186 \mathrm{mg} / \mathrm{g}$ $(\mathrm{CV})$, and $111 \mathrm{mg} / \mathrm{g}(\mathrm{RB})$. Thermal regeneration studies for $\mathrm{MB}$ on $\mathrm{W}-\mathrm{HF}$ showed that the efficiency decreased slightly from $100 \%$ to $99 \%$ after third cycle. W-HF has also been able to successfully remove the combination of dyes from the solutions with no selective adsorption.

\section{ACKNOWLEDGMENT}

The authors are thankful to Tugce Semerci and Huseyin Ozgener (Izmir Institute of Technology) for FTIR analysis. C.V. and D.Z. gratefully acknowledge the support of TUBITAK (The Scientific and Technological Research Council of Turkey) under the project Grant No: CAYDAG-113Y533.

\section{ORCID}

Damla Zeydanli iD http://orcid.org/0000-0002-7069-6088 Cekdar Vakifahmetoglu iD http://orcid.org/0000-0003-12224362

\section{REFERENCES}

1. Alyüz B, Veli S. Kinetics and equilibrium studies for the removal of nickel and zinc from aqueous solutions by ion exchange resins. J Hazard Mater. 2009;167:482-488.

2. Huang $\mathrm{H}$, Zhang J, Jiang L, Zang Z. Preparation of cubic $\mathrm{Cu} 2 \mathrm{O}$ nanoparticles wrapped by reduced graphene oxide for the efficient removal of rhodamine B. J Alloy Compd. 2017;718:112-115.

3. Hojamberdiev M, Prasad RM, Morita K, Schiavon MA, Riedel R. Polymer-derived mesoporous $\mathrm{SiOC} / \mathrm{ZnO}$ nanocomposite for the purification of water contaminated with organic dyes. Microporous Mesoporous Mater. 2012;151:330-338.

4. Chen Q, Luo Z, Hills C, Xue G, Tyrer M. Precipitation of heavy metals from wastewater using simulated flue gas: sequent additions of fly ash, lime and carbon dioxide. Water Res. 2009;43:2605-2614.

5. Charerntanyarak L. Heavy metals removal by chemical coagulation and precipitation. Water Sci Technol. 1999;39:135-138.

6. Ahmad AL, Ooi BS. A study on acid reclamation and copper recovery using low pressure nanofiltration membrane. Chem Eng J. 2010;156:257-263.
7. Barakat M, Schmidt E. Polymer-enhanced ultrafiltration process for heavy metals removal from industrial wastewater. Desalination. 2010;256:90-93.

8. Sudilovskiy P, Kagramanov G, Kolesnikov V. Use of RO and $\mathrm{NF}$ for treatment of copper containing wastewaters in combination with flotation. Desalination. 2008;221:192-201.

9. Baysal A, Ozbek N, Akman S. Determination of trace metals in waste water and their removal processes. In: Einschlag F, Carlos L, eds. Waste Water - Treatment Technologies and Recent Analytical Developments. Rijeka, Croatia: InTech; 2013:p. Ch. 07.

10. Fu F, Wang Q. Removal of heavy metal ions from wastewaters: a review. J Environ Manage. 2011;92:407-418.

11. Emamjomeh MM, Sivakumar M. Review of pollutants removed by electrocoagulation and electrocoagulation/flotation processes. $J$ Environ Manage. 2009;90:1663-1679.

12. Grassi M, Kaykioglu G, Belgiorno V, Lofrano G. Emerging compounds removal from wastewater. Springer Briefs Green Chem Sustain. 1007;2012:978-994.

13. Gupta VK, Kumar R, Nayak A, Saleh TA, Barakat MA. Adsorptive removal of dyes from aqueous solution onto carbon nanotubes: a review. Adv Coll Interface Sci. 2013;193-194(Supplement C):24-34.

14. Gupta VK. Suhas. Application of low-cost adsorbents for dye removal - A review. J Environ Manage. 2009;90:2313-2342.

15. Wan Ngah WS, Teong LC, Hanafiah MAKM. Adsorption of dyes and heavy metal ions by chitosan composites: a review. Carbohyd Polym. 2011;83:1446-1456.

16. Boonamnuayvitaya V, Chaiya C, Tanthapanichakoon W, Jarudilokkul S. Removal of heavy metals by adsorbent prepared from pyrolyzed coffee residues and clay. Sep Purif Technol. 2004;35:11-22.

17. Celis R, HermosÍn MC, Cornejo J. Heavy Metal Adsorption by Functionalized Clays. Environ Sci Technol. 2000;34:4593-4599.

18. Almeida CAP, Debacher NA, Downs AJ, Cottet L, Mello CAD. Removal of methylene blue from colored effluents by adsorption on montmorillonite clay. J Colloid Interface Sci. 2009;332:46-53.

19. Pehlivan E, Cetin S, Yanık BH. Equilibrium studies for the sorption of zinc and copper from aqueous solutions using sugar beet pulp and fly ash. $J$ Hazard Mater. 2006;135:193-199.

20. Erdem E, Karapinar N, Donat R. The removal of heavy metal cations by natural zeolites. J Colloid Interface Sci. 2004;280:309-314.

21. Covarrubias C, García R, Arriagada R, Yánez J, Garland MT. Cr (III) exchange on zeolites obtained from kaolin and natural mordenite. Microporous Mesoporous Mater. 2006;88:220-231.

22. Üçer A, Uyanik A, Aygün ŞF. Adsorption of $\mathrm{Cu}(\mathrm{II}), \mathrm{Cd}(\mathrm{II}), \mathrm{Zn}$ (II), $\mathrm{Mn}(\mathrm{II})$ and $\mathrm{Fe}(\mathrm{III})$ ions by tannic acid immobilised activated carbon. Sep Purif Technol. 2006;47:113-118.

23. Mohan D, Singh KP. Single- and multi-component adsorption of cadmium and zinc using activated carbon derived from bagassean agricultural waste. Water Res. 2002;36:2304-2318.

24. Zhang S, Shao T, Karanfil T, Pan B. The correlation between structural characteristics of activated carbons and their adsorption of organic solutes from aqueous solutions. Adsorption. 2012;18:229-238.

25. Yuan Z-Y, Ren T-Z, Su B-L. CO2-induced micro-construction of hierarchical strings of mesoporous silica spheroids. Chem Phys Lett. 2004;383:348-352.

26. Machida M, Fotoohi B, Amamo Y, Ohba T, Kanoh H, Mercier L. Cadmium(II) adsorption using functional mesoporous silica and activated carbon. J Hazard Mater. 2012;221-222(Supplement C):220-227. 
27. Ho KY, McKay G, Yeung KL. Selective adsorbents from ordered mesoporous silica. Langmuir. 2003;19:3019-3024.

28. Aygün A, Yenisoy-Karakaş S, Duman I. Production of granular activated carbon from fruit stones and nutshells and evaluation of their physical, chemical and adsorption properties. Microporous Mesoporous Mater. 2003;66:189-195.

29. Girgis BS, Smith E, Louis MM. El-Hendawy A-NA. Pilot production of activated carbon from cotton stalks using H3PO4. $J$ Anal Appl Pyrol. 2009;86:180-184.

30. Senthilkumaar S, Kalaamani P, Subburaam CV. Liquid phase adsorption of Crystal violet onto activated carbons derived from male flowers of coconut tree. J Hazard Mater. 2006;136:800-808.

31. Li L, Liu S, Zhu T. Application of activated carbon derived from scrap tires for adsorption of Rhodamine B. J Environ Sci. 2010;22:1273-1280.

32. Meena AK, Mishra GK, Rai PK, Rajagopal C, Nagar PN. Removal of heavy metal ions from aqueous solutions using carbon aerogel as an adsorbent. J Hazard Mater. 2005;122:161-170.

33. Kadirvelu K, Goel J, Rajagopal C. Sorption of lead, mercury and cadmium ions in multi-component system using carbon aerogel as adsorbent. J Hazard Mater. 2008;153:502-507.

34. Sui Z, Meng Q, Zhang X, Ma R, Cao B. Green synthesis of carbon nanotube-graphene hybrid aerogels and their use as versatile agents for water purification. J Mater Chem. 2012;22:8767-8771.

35. Vakifahmetoglu C, Zeydanli D, Colombo P. Porous polymer derived ceramics. Mater Sci Eng R Rep. 2016;106(Supplement C):1-30.

36. Haug R, Weinmann M, Bill J, Aldinger F. Plastic forming of preceramic polymers. J Eur Ceram Soc. 1999;19:1-6.

37. Vakifahmetoglu C. Fabrication and properties of ceramic 1D nanostructures from preceramic polymers: a review. Adv Appl Ceram. 2011;110:188-204.

38. Vakifahmetoglu C, Zeydanli D, Innocentini MD, Ribeiro FD, Lasso PRO, Soraru GD. Gradient-hierarchic-aligned porosity SiOC ceramics. Sci Rep. 2017;7:41049.

39. Tolosa A, Krüner B, Jäckel N, Aslan M, Vakifahmetoglu C, Presser V. Electrospinning and electrospraying of silicon oxycarbide-derived nanoporous carbon for supercapacitor electrodes. $J$ Power Sources. 2016;313:178-188.

40. Presser V, Yeon SH, Vakifahmetoglu C, et al. Hierarchical porous carbide-derived carbons for the removal of cytokines from blood plasma. Adv Healthc Mater. 2012;1:796-800.

41. Bruzzoniti MC, Appendini M, Rivoira L, et al. Polymer-derived ceramic aerogels as sorbent materials for the removal of organic dyes from aqueous solutions. J Am Ceram Soc. 2017;101:1-10.

42. Pan J, Ren J, Xie Y, et al. Porous SiOC composites fabricated from preceramic polymers and wood powders for efficient dye adsorption and removal. Res Chem Intermed. 2017;43:3813-3832.

43. Chemicalize. 2017; Available from: https://chemicalize.com/.

44. Vakifahmetoglu C, Zeydanli D, Ozalp VC, Borsa BA, Soraru GD. Hierarchically porous polymer derived ceramics: a promising platform for multidrug delivery systems. Mater Des. 2018;140:37-44.

45. Vakifahmetoglu C, Buldu M, Karakuscu A, Ponzoni A, Assefa D, Soraru GD. High surface area carbonous components from emulsion derived SiOC and their gas sensing behavior. $J$ Eur Ceram Soc. 2015;35:4447-4452.

46. Hassan MM, Takahashi T, Koyama K. Preparation and characterisation of SiOC ceramics made from a preceramic polymer and rice bran. J Eur Ceram Soc. 2013;33:1207-1217.
47. Bushra R, Ahmed A, Shahadat M. Chapter 5. Mechanism of Adsorption on Nanomaterials. In: Advanced Environmental Analysis: Applications of Nanomaterials. Vol 1. London, UK: The Royal Society of Chemistry; 2017:90-111.

48. Assefa D, Zera E, Campostrini R, Soraru GD, Vakifahmetoglu C. Polymer-derived SiOC aerogel with hierarchical porosity through HF etching. Ceram Int. 2016;42:11805-11809.

49. Monash P, Pugazhenthi G. Adsorption of crystal violet dye from aqueous solution using mesoporous materials synthesized at room temperature. Adsorption. 2009;15:390-405.

50. Karim A, Jalil AA, Triwahyono $\mathrm{S}$, et al. Amino modified mesostructured silica nanoparticles for efficient adsorption of methylene blue. J Colloid Interface Sci. 2012;386:307-314.

51. Mohammadi M, Hassani AJ, Mohamed AR, Najafpour GD. Removal of rhodamine B from aqueous solution using palm shell-based activated carbon: adsorption and kinetic studies. $J$ Chem Eng Data. 2010;55:5777-5785.

52. Ducheyne P, Healy K, Hutmacher DW, Grainger DW, Kirkpatrick CJ. Comprehensive Biomaterials. Vol 1. Amsterdam, The Netherlands: Elsevier Science; 2015.

53. Liu H, Liu H. Selective dye adsorption and metal ion detection using multifunctional silsesquioxane-based tetraphenylethenelinked nanoporous polymers. J Mater Chem A Mater Energy Sustain. 2017;5:9156-9162.

54. Turabik M. Adsorption of basic dyes from single and binary component systems onto bentonite: simultaneous analysis of Basic Red 46 and Basic Yellow 28 by first order derivative spectrophotometric analysis method. J Hazard Mater. 2008;158:52-64.

55. Wang S, Li H, Xie S, Liu S, Xu L. Physical and chemical regeneration of zeolitic adsorbents for dye removal in wastewater treatment. Chemosphere. 2006;65:82-87.

56. Sun Z, Li C, Wu D. Removal of methylene blue from aqueous solution by adsorption onto zeolite synthesized from coal fly ash and its thermal regeneration. $J$ Chem Technol Biotechnol. 2010;85:845-850.

57. Chen D, Zeng Z, Zeng Y, Zhang F, Wang M. Removal of methylene blue and mechanism on magnetic $\gamma$ - $\mathrm{Fe} 2 \mathrm{O} 3 / \mathrm{SiO} 2$ nanocomposite from aqueous solution. Water Resour Ind. 2016;15(Supplement C):1-13.

58. Meng L, Zhang X, Tang Y, Su K, Kong J. Hierarchically porous silicon-carbon-nitrogen hybrid materials towards highly efficient and selective adsorption of organic dyes. Sci Rep. 2015;5:7910.

\section{SUPPORTING INFORMATION}

Additional Supporting Information may be found online in the supporting information tab for this article.

How to cite this article: Zeydanli D, Akman S, Vakifahmetoglu C. Polymer-derived ceramic adsorbent for pollutant removal from water. $J \mathrm{Am}$ Ceram Soc. 2018;101:2258-2265. https://doi.org/ $\underline{10.1111 / \text { jace. } 15423}$ 